\title{
Performance based design of reinforced concrete beams under impact
}

\author{
S. Tachibana ${ }^{1}$, H. Masuya ${ }^{2}$, and S. Nakamura ${ }^{3}$ \\ ${ }^{1}$ Hokukon Co., Ltd., Fukui, Japan \\ ${ }^{2}$ Faculty of Environmental Design, Institute of Science and Engineering, Kanazawa University, Kanazawa, Japan \\ ${ }^{3}$ Nihon Samicon Co., Ltd., Niigata, Japan
}

Received: 14 January 2009 - Revised: 21 April 2010 - Accepted: 7 May 2010 - Published: 1 June 2010

\begin{abstract}
The purpose of this research is to collect fundamental data and to establish a performance-based design method for reinforced concrete beams under perpendicular impact load.

Series of low speed impact experiments using reinforced concrete beams were performed varying span length, cross section and main reinforcement.

The experimental results are evaluated focusing on the impact load characteristics and the impact behaviours of reinforced concrete beams. Various characteristic values and their relationships are investigated such as the collision energy, the impact force duration, the energy absorbed by the beams and the beam response values. Also the bending performance of the reinforced concrete beams against perpendicular impact is evaluated.

An equation is proposed to estimate the maximum displacement of the beam based on the collision energy and the static ultimate bending strength. The validity of the proposed equation is confirmed by comparison with experimental results obtained by other researchers as well as numerical results obtained by FEM simulations. The proposed equation allows for a performance based design of the structure accounting for the actual deformation due to the expected impact action.
\end{abstract}

\section{Introduction}

Many mountainous areas in Japan present severe risks due to natural hazards as rockfall, frequent earthquakes, landslides and avalanches. About $70 \%$ of the land has a steep slope and is exposed to frequent rain or snow. Protection measures against rockfall are among the most important mea-

Correspondence to: H. Masuya

(masuya@kenroku.kanazawa-u.ac.jp) sures in preventing incidents, as the one illustrated in Fig. 1. Therefore, many protective structures have been constructed in mountainous areas (Masuya, 2005; Japan Road Association, 2000; Japan Railway Civil Engineering Association, 1978). The dynamic behavior of these structures under impact is generally very complex and closely related to the type of structure and the characteristic of material used. Furthermore, there are still difficulties in the design of the protective structures because many problems concerning the structural impact behavior and dynamic material properties of concrete, steel and of the sand cushion layer are unsolved yet. The subcommittee of impact problems of JSCE (2004) had therefore designated the examination of impact experimental and analysis methods as one of the priorities for standardization. The committee aimed for proposing a general impact test and measurement method and for showing the efficiency of numerical methods to reproduce the dynamic behavior of the structures.

Delhomme et al. (2005) performed impact experiments of a rockfall protection structure with a special structural energy dissipating system. Schellenberg $(2007,2009)$ showed a physical numerical model to express the interaction between a rockfall and the structure based on experiments. The present study provides experimental data concerning the dynamic behavior of protection structures to a higher level of damage. Several impact experiments have primarily been performed to study the dynamic behavior of structural members such as reinforced concrete beams. The experiments clarified the fundamental knowledge about experimental and measuring methods (Yamamoto et al., 2001; Nakata et al., 2002; Kishi et al., 2003; Tachibana et al., 2006). The final purpose of this study is to establish a methodology for the performance based design of structures (Subcommittee concerning performance based design of structures against impact action of JSCE, 2007).

Published by Copernicus Publications on behalf of the European Geosciences Union. 


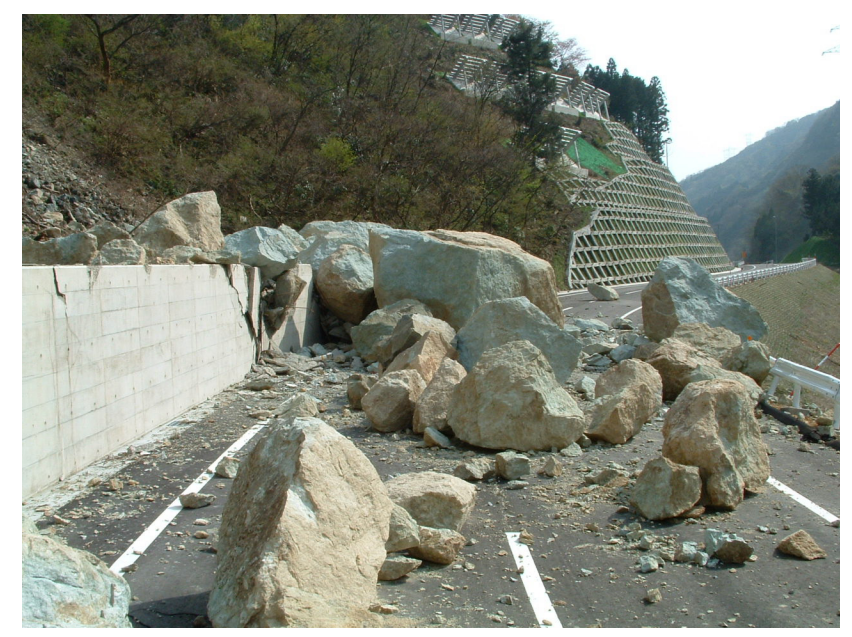

Fig. 1. Rockfall event on road N364, Kaga, December 2004.

Rock sheds are some of the protection structures subjected to impacts. Their roofs are made of either slab or beam structures. Generally, a layer of cushion material is used as shock absorber on top of the roof. As a result, compared with other dynamic actins, rockfall is in many cases a slow impact. Therefore, for rock sheds bending failure of the beams becomes dominant in most of the cases. For the prestressed concrete rock sheds, Masuya and Yamamoto (1999) showed design load factors for the expected limit states including bending failure. Sonoda (1999) showed the ultimate limit states of rock sheds and proposed a design method by means of a simple motion model expressing the bending failure.

In this research the impact behaviours of a reinforced concrete beam was studied evaluated for such bending failures.

Experiments on reinforced concrete beams were performed with the purpose of collecting fundamental data to establish a performance based design method for protection structures under impact loading. The characteristics of reinforced concrete beams under impact loading are shown. Further, it is suggested to an use of evaluation method predicting the maximum beam displacements based on the velocity of the impacting weight and the static ultimate bending capacity of the reinforced concrete beam.

\section{Impact experiments}

\subsection{Specimen}

Several series of impact tests were carried out using various reinforced concrete beams with shear reinforcement. Details of the beams and the reinforcement arrangement are shown in Fig. 2. Table 1 shows the design values of the different specimen.

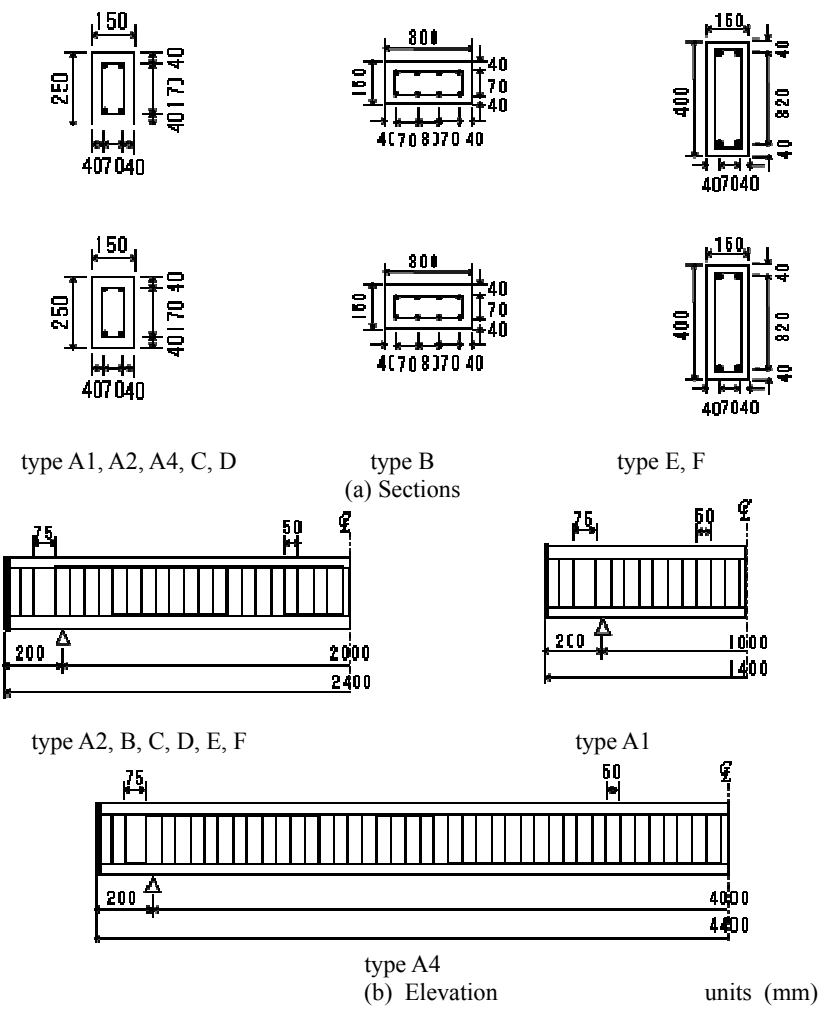

Fig. 2. Details of reinforced concrete beams.

All beams have rectangular sections with the main reinforcement arranged at the top and bottom sides and a shear reinforcement of 6-mm diameter (D6). The main reinforcement is welded to steel plates at the beam ends. The beam types $\mathrm{A}, \mathrm{C}$ and $\mathrm{D}$ have the same sections with a width of $150 \mathrm{~mm}$ and a height of $250 \mathrm{~mm}$. For types $\mathrm{A} 1, \mathrm{~A} 2$ and A4, the span length is $1000 \mathrm{~mm}, 2000 \mathrm{~mm}$ and $4000 \mathrm{~mm}$, respectively. For the beams type A, B and E, the diameter of the main reinforcement is $13 \mathrm{~mm}$ (D13). Diameter bars of $16 \mathrm{~mm}$ (D16) are used for type C and diameter $10 \mathrm{~mm}$ (D10) for types $\mathrm{D}$ and $\mathrm{F}$.

The design strength of concrete is $24 \mathrm{MPa}$. The yield stress of the reinforcement is $345 \mathrm{MPa}$ for the bending bars and $295 \mathrm{MPa}$ for the stirrups, respectively. The static ultimate bending capacities $P_{\mathrm{u}}$ of the beam types B, F and A2 are comparable, while bending capacities of the beam types $\mathrm{C}$ and $\mathrm{E}$ are larger and the one of type $\mathrm{D}$ is smaller. The ultimate shear capacity $V_{\mathrm{u}}$ in all beams is larger than the ratio of capacity $\left(\gamma=\left(V_{\mathrm{u}} / P_{\mathrm{u}}\right)>1\right)$. Namely, the bending failure is preceding the shear failure for static load in all cases.

\subsection{Test setup}

Figure 3 shows the apparatus used for the falling weight impact experiments. The reinforced concrete beams are impacted by a steel weight, which is dropped from a specific height. The weight used in the experiments have a curved 
Table 1. Design values of reinforced concrete beams.

\begin{tabular}{|c|c|c|c|c|c|c|c|}
\hline \multirow[t]{2}{*}{$\begin{array}{l}\text { Beam } \\
\text { type }\end{array}$} & $\begin{array}{l}\text { Width } \\
\mathrm{x} \text { height } \\
\mathrm{x} \text { span }\end{array}$ & $\begin{array}{l}\text { Diameter } \\
\text { of bending } \\
\text { reinforcement }\end{array}$ & $\begin{array}{l}\text { Ultimate } \\
\text { bending } \\
\text { capacity }\end{array}$ & $\begin{array}{l}\text { Ultimate } \\
\text { shear } \\
\text { capacity }\end{array}$ & $\begin{array}{l}\text { Ratio of } \\
\text { capacities }\end{array}$ & $\begin{array}{l}\text { Bending } \\
\text { stiffness }\end{array}$ & $\begin{array}{l}\text { Natural } \\
\text { period }\end{array}$ \\
\hline & $(\mathrm{m})$ & & $P_{\mathrm{u}}(\mathrm{kN})$ & $V_{\mathrm{u}}(\mathrm{kN})$ & $\gamma=\left(V_{\mathrm{u}} / P_{\mathrm{u}}\right)$ & $\mathrm{EI}_{\mathrm{u}}\left(\mathrm{kN} \mathrm{m}^{2}\right)$ & $T_{0}(\mathrm{~ms})$ \\
\hline A1 & $0.15 \times 0.25 \times 1$ & D13 & 66.7 & 91.1 & 1.4 & 5729 & 2.5 \\
\hline A 2 & $0.15 \times 0.25 \times 2$ & D13 & 33.3 & 91.1 & 2.7 & 5729 & 10.0 \\
\hline A4 & $0.15 \times 0.25 \times 4$ & D13 & 16.7 & 91.1 & 5.5 & 5729 & 40.1 \\
\hline B & $0.30 \times 0.15 \times 2$ & D13 & 31.8 & 65.9 & 2.1 & 2412 & 16.9 \\
\hline $\mathrm{C}$ & $0.15 \times 0.25 \times 2$ & D16 & 50.3 & 94.8 & 1.9 & 6088 & 9.7 \\
\hline $\mathrm{D}$ & $0.15 \times 0.25 \times 2$ & D10 & 20.2 & 87.1 & 4.3 & 5342 & 10.4 \\
\hline $\mathrm{E}$ & $0.15 \times 0.40 \times 2$ & D13 & 59.5 & 145.6 & 2.4 & 22900 & 6.3 \\
\hline $\mathrm{F}$ & $0.15 \times 0.40 \times 2$ & D10 & 34.9 & 140.6 & 4.0 & 21590 & 6.5 \\
\hline
\end{tabular}

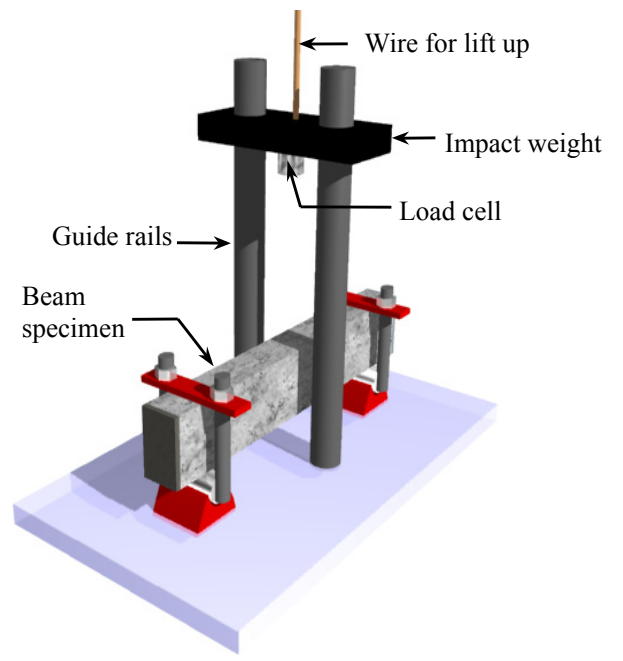

Fig. 3. Apparatus used for experiments.

contact surface with a length of $565 \mathrm{~mm}$, a radius of $75 \mathrm{~mm}$ and masses of $150 \mathrm{~kg}, 300 \mathrm{~kg}$ or $450 \mathrm{~kg}$. The weights fall along two guiding rails. Special tie-down steel frames were installed on both supports preventing the beam from bouncing off the supports. Measured items were the impact force, the reaction forces at the supports, displacements of the beam and strains in the reinforcement. Measurements and their positions are shown in the Fig. 4. All output data was recorded with a rate of $20 \mathrm{kHz}$ by means of a digital recorder (DR-M3 TEAC Co.).

Table 2 summarizes the conducted impact experiments considered in this paper. Two series of experiments were performed for specimen of type A2 with different combinations of impact mass and velocity. One series is performed varying the momentum and the other series varying the kinetic energy. For the specimen other than type A2, tests were performed under constant conditions in which the mass is $300 \mathrm{~kg}$ and the impact velocity is $5 \mathrm{~m} / \mathrm{s}$.

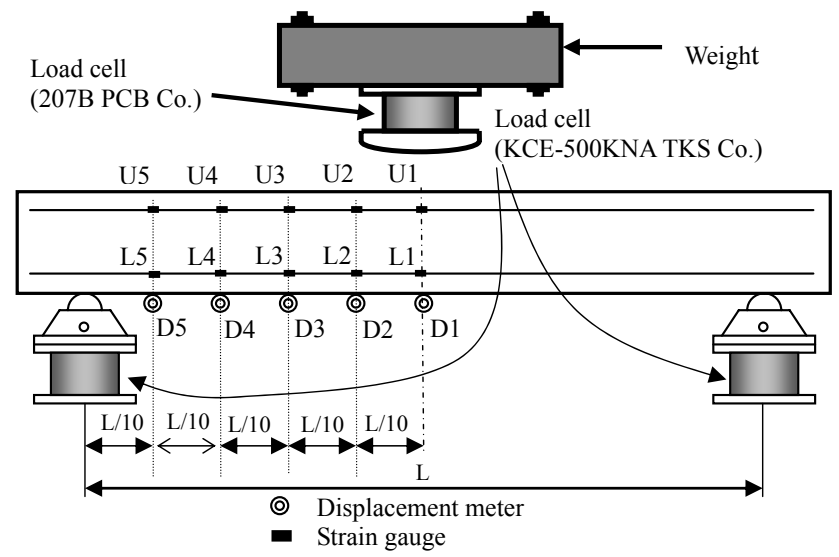

Fig. 4. Measurement items.

\section{Experimental results}

\subsection{Characteristic values of impact}

Figure 5 shows the time response of impact force, impact force-displacement curve and characteristic values resulted from those relations:

- Impulse $I_{\mathrm{p}}$ : integration of force-time curve.

- The absorbed energy $E_{\mathrm{p}}$ : integration of forcedisplacement curve.

- The mean impact force $P_{\mathrm{m}}$ : impulse $I_{\mathrm{p}}$ divided by duration of impact force $T_{\mathrm{d}}$.

The results of the impact experiments (Table 3 ) are correlated with the energy consumed by the deformation of the beams. For the experiments Nos. 10-21 average values of several experiments are shown. 
(a)

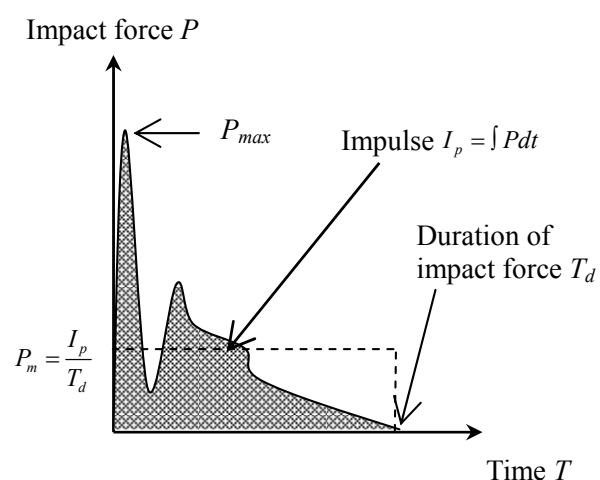

(b)

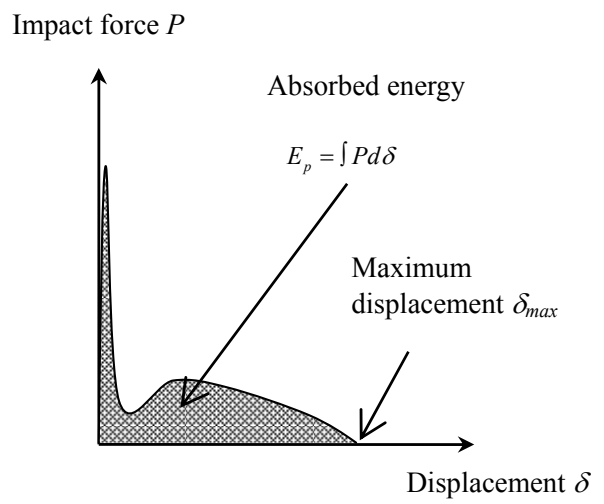

Fig. 5. Characteristic values. (a) Time response of impact force. (b) Force-displacement curve.

Table 2. Overview of impact tests.

\begin{tabular}{|c|c|c|c|c|c|c|}
\hline No. & $\begin{array}{l}\text { Speci- } \\
\text { men }\end{array}$ & $\begin{array}{l}\text { Falling } \\
\text { weight } \\
m \\
(\mathrm{~kg})\end{array}$ & $\begin{array}{l}\text { Impact } \\
\text { velocity } \\
V_{\text {col }} \\
(\mathrm{m} / \mathrm{s})\end{array}$ & $\begin{array}{l}\text { Kinetic } \\
\text { energy } \\
E_{\text {col }} \\
(\mathrm{J})\end{array}$ & $\begin{array}{l}\text { Momen- } \\
\text { tum } \\
M_{\text {col }} \\
(\mathrm{N} \mathrm{s})\end{array}$ & $\begin{array}{l}\text { No. of } \\
\text { beams }\end{array}$ \\
\hline 1 & A2 & 150 & 3.5 & 900 & 520 & 1 \\
\hline 2 & A2 & 300 & 2.4 & 900 & 735 & 1 \\
\hline 3 & $\mathrm{~A} 2$ & 450 & 2 & 900 & 900 & 1 \\
\hline 4 & $\mathrm{~A} 2$ & 150 & 4.9 & 1800 & 735 & 1 \\
\hline 5 & $\mathrm{~A} 2$ & 300 & 3.5 & 1800 & 1039 & 1 \\
\hline 6 & $\mathrm{~A} 2$ & 450 & 2.8 & 1800 & 1273 & 1 \\
\hline 7 & A2 & 150 & 6 & 2700 & 900 & 1 \\
\hline 8 & $\mathrm{~A} 2$ & 300 & 4.2 & 2700 & 1273 & 1 \\
\hline 9 & A2 & 450 & 3.5 & 2700 & 1559 & 1 \\
\hline 10 & $\mathrm{~A} 2$ & 300 & 1 & 150 & 300 & 1 \\
\hline 11 & $\mathrm{~A} 2$ & 300 & 2 & 600 & 600 & 2 \\
\hline 12 & $\mathrm{~A} 2$ & 300 & 3 & 1350 & 900 & 2 \\
\hline 13 & $\mathrm{~A} 2$ & 300 & 4 & 2400 & 1200 & 2 \\
\hline 14 & $\mathrm{~A} 2$ & 300 & 5 & 3750 & 1500 & 3 \\
\hline 15 & A1 & 300 & 5 & 3750 & 1500 & 4 \\
\hline 16 & A4 & 300 & 5 & 3750 & 1500 & 3 \\
\hline 17 & B & 300 & 5 & 3750 & 1500 & 2 \\
\hline 18 & $\mathrm{C}$ & 300 & 5 & 3750 & 1500 & 2 \\
\hline 19 & $\mathrm{D}$ & 300 & 5 & 3750 & 1500 & 2 \\
\hline 20 & $\mathrm{E}$ & 300 & 5 & 3750 & 1500 & 2 \\
\hline 21 & $\mathrm{~F}$ & 300 & 5 & 3750 & 1500 & 2 \\
\hline
\end{tabular}

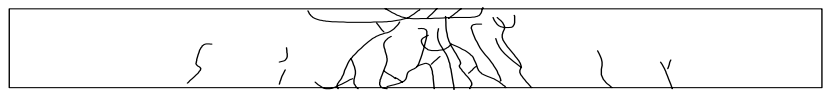

Fig. 6. Crack pattern for test No. 14 (type A2, beam $m=300 \mathrm{~kg}$, $\left.V_{\mathrm{col}}=5 \mathrm{~m} / \mathrm{s}\right)$.

Figure 6 shows the crack pattern from a beam of type A2 after the impact a mass of $300 \mathrm{~kg}$ and a velocity of $5 \mathrm{~m} / \mathrm{s}$. It is a typical crack pattern for bending failure with small concrete fragmentation at the impact position.
Table 3. Experimental results.

\begin{tabular}{|c|c|c|c|c|c|c|}
\hline No. & $\begin{array}{l}\text { Maxi- } \\
\text { mum } \\
\text { impact } \\
\text { force }\end{array}$ & Impulse & $\begin{array}{l}\text { Duration } \\
\text { time of } \\
\text { impact } \\
\text { force }\end{array}$ & $\begin{array}{l}\text { Mean } \\
\text { impact } \\
\text { force }\end{array}$ & $\begin{array}{l}\text { Absorbed } \\
\text { energy }\end{array}$ & $\begin{array}{l}\text { Maxi- } \\
\text { mum } \\
\text { displa- } \\
\text { cement }\end{array}$ \\
\hline & $\begin{array}{l}P_{\max } \\
(\mathrm{kN})\end{array}$ & $\begin{array}{l}I_{\mathrm{p}} \\
(\mathrm{Ns})\end{array}$ & $\begin{array}{l}T_{\mathrm{d}} \\
(\mathrm{ms})\end{array}$ & $\begin{array}{l}P_{\mathrm{m}} \\
(\mathrm{kN})\end{array}$ & $\begin{array}{l}E_{\mathrm{p}} \\
(\mathrm{J})\end{array}$ & $\begin{array}{l}\delta_{\max } \\
(\mathrm{mm})\end{array}$ \\
\hline 1 & 320.5 & 945.3 & 23.9 & 39.6 & 684.9 & 13.6 \\
\hline 2 & 293.4 & 1240.3 & 25.4 & 48.9 & 836.4 & 25.4 \\
\hline 3 & 245.3 & 1376.4 & 28.3 & 48.7 & 886.9 & 37.0 \\
\hline 4 & 453.4 & 1096.4 & 26.7 & 41.1 & 1594.0 & 16.3 \\
\hline 5 & 416.5 & 1459.9 & 34.0 & 43.0 & 1792.3 & 31.6 \\
\hline 6 & 345.6 & 1798.3 & 37.7 & 47.8 & 1684.1 & 43.7 \\
\hline 7 & 572.8 & 1365.7 & 33.9 & 40.3 & 1709.3 & 17.9 \\
\hline 8 & 513.3 & 1896.6 & 42.4 & 44.7 & 2058.6 & 33.3 \\
\hline 9 & 444.6 & 2199.4 & 47.5 & 46.3 & 2681.8 & 48.4 \\
\hline 10 & 65.4 & 674.5 & 25.9 & 26.1 & 155.6 & 4.5 \\
\hline 11 & 253.2 & 796.1 & 24.5 & 32.6 & 472.6 & 12.6 \\
\hline 12 & 426.2 & 1277.0 & 33.3 & 38.3 & 1217.7 & 26.9 \\
\hline 13 & 489.3 & 1525.3 & 37.7 & 40.5 & 2512.3 & 41.4 \\
\hline 14 & 466.2 & 1940.2 & 41.6 & 46.7 & 3072.4 & 58.3 \\
\hline 15 & 434.0 & 1976.5 & 18.6 & 106.4 & 3103.3 & 24.1 \\
\hline 16 & 451.5 & 1851.2 & 105.6 & 17.5 & 2538.7 & 114.9 \\
\hline 17 & 667.1 & 2039.7 & 57.8 & 35.4 & 3338.3 & 77.0 \\
\hline 18 & 650.3 & 1988.4 & 32.9 & 60.6 & 2847.5 & 42.4 \\
\hline 19 & 638.7 & 1906.7 & 63.0 & 30.3 & 3735.1 & 94.0 \\
\hline 20 & 742.2 & 1830.0 & 25.3 & 72.5 & 2518.0 & 29.1 \\
\hline 21 & 663.5 & 1655.6 & 33.8 & 49.0 & 2043.2 & 43.9 \\
\hline
\end{tabular}

Note: No. 10 to No. 21 show average values.

\subsection{Impulse and duration of impact force}

Figure 7a shows the impulse $I_{\mathrm{p}}$ in relation to the ultimate bending strength $P_{\mathrm{u}}$ for experiments with a constant momentum at the time of collision of $1500 \mathrm{Ns}$. The impulse are about 2000 Ns and do not vary with the type of the beams. Therefore, it can be expected that the impulse depends on the momentum at the time of collision. Figure $7 \mathrm{~b}$ shows the relation between the momentum of the weight and the impulse. This relationship can be expressed with the following 
(a)

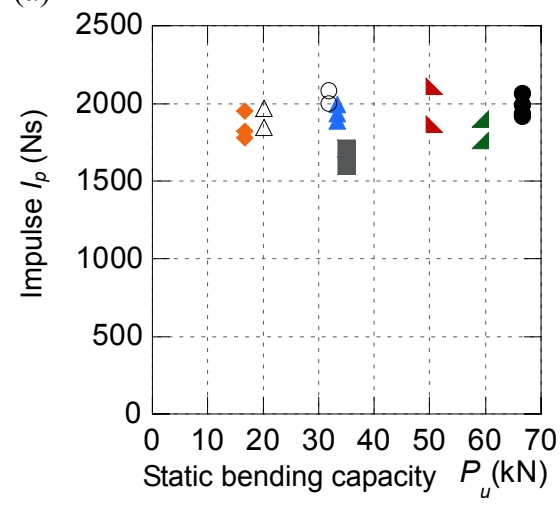

(b)

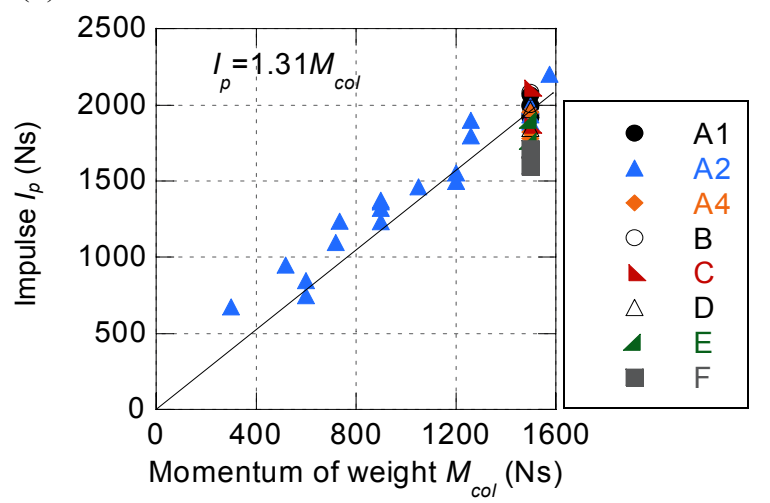

Fig. 7. Relationship between static bending capacity, momentum of weight and impulse. (a) Static bending capacity. (b) Momentum of weight.

equation.

$I_{\mathrm{p}}=1.31 M_{\mathrm{col}}$.

Since rebounds were observed in all experiments, it is supposed that the value 1.31 expresses this effect. The physical amount of impulse $I_{\mathrm{P}}$ was $31 \%$ higher than the initial momentum of weight $M_{\text {col }}$. Therefore, the weight obtains a upward vertical velocity.

Figure $8 \mathrm{a}$ shows the impact force duration $T_{\mathrm{d}}$ in relation to the ultimate bending capacity of the specimen for the experiments with a momentum at the time of collision of $1500 \mathrm{Ns}$. A tendency is observed that the impact force duration $T_{\mathrm{d}}$ is decreasing when the static ultimate bending capacity is increasing. The displacement had reached the plastic range in all specimens. It was also revealed that the impact force duration is proportional to the momentum of weight at the time of collision. Hence, the impact force duration is proportional to the ratio of the momentum of the weight divided by the static ultimate bending capacity $M_{\mathrm{col}} / P_{\mathrm{u}}$ shown in Fig. 8b. The graph can be expressed with the following equation.

$T_{\mathrm{d}}=1.06 M_{\mathrm{col}} / P_{\mathrm{u}}$. (a)

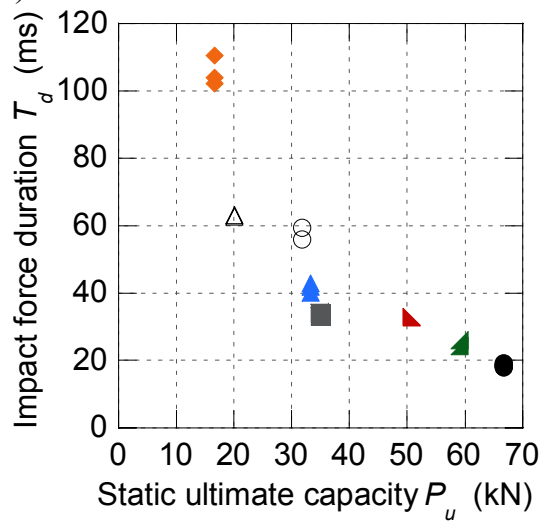

(b)

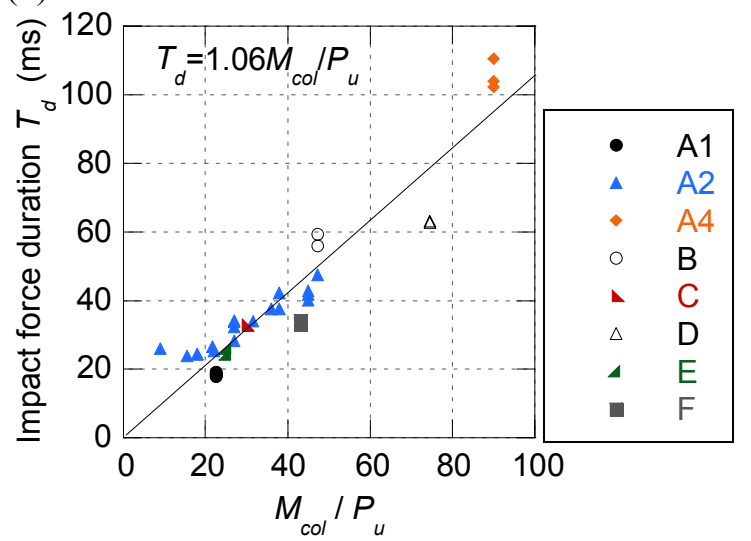

Fig. 8. Relationship between the duration of impact force and static ultimate bending capacity, the ratio of the momentum of the weight at the time of collision. (a) Static ultimate bending capacity. (b) Ratio of momentum of weight to static ultimate bending capacity.

It is noted that this equation is not valid for smaller impact intensities where the beam remains in the elastic range and no plastic deformations occur.

\subsection{Maximum displacement of the beam}

Figure 9 shows the time response of the displacement at the midspan for the case of a beam type A2 impacted by a mass of weight of $300 \mathrm{~kg}$ and a velocity of $V_{\mathrm{col}}=5 \mathrm{~m} / \mathrm{s}$. Large plastic strains are observed in the main reinforcement that resulted in large remaining displacements.

Figure 10 shows the relationship between the mean impact force $P_{m}$ and the maximum displacement $\delta_{\max }$ at midspan. In the case of an impact energy of $E_{\mathrm{col}}=3750 \mathrm{~J}$, it is observed that the mean impact force $P_{\mathrm{m}}$ decreases with increasing maximum displacements in an inverse proportion. The two lines shown in Fig. 10 indicate the approximation curve for the impact with energies $E_{\mathrm{col}}=3750$ and $1800 \mathrm{~J}$. Thus, the 


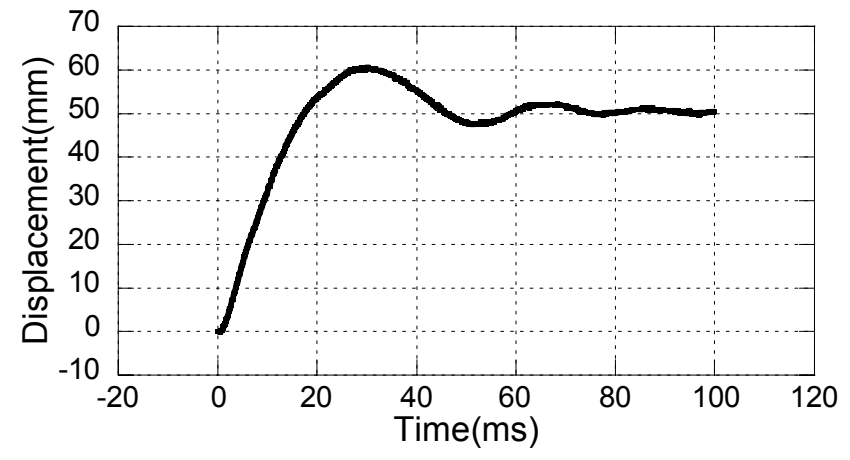

Fig. 9. Time response of the displacement at midspan for test No. 14 (type $\mathrm{A} 2, \mathrm{~m}=300 \mathrm{~kg}, V_{\mathrm{col}}=5 \mathrm{~m} / \mathrm{s}$ ).

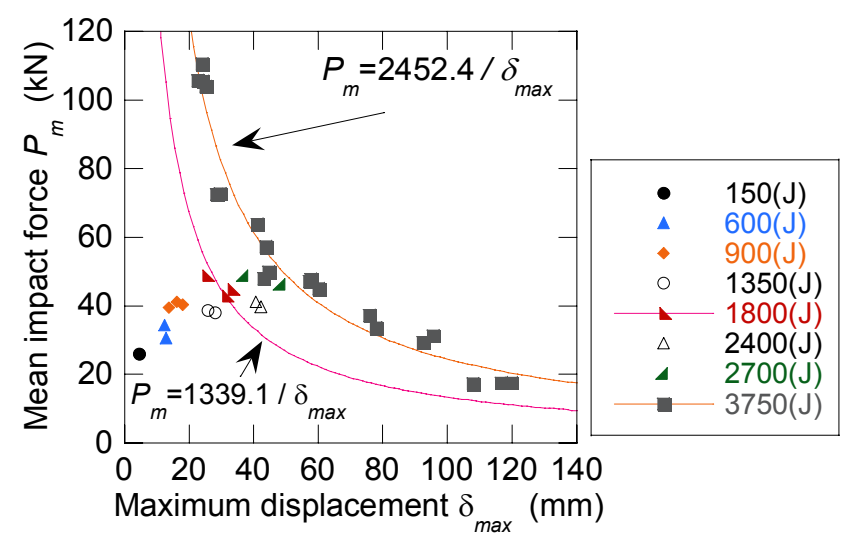

Fig. 10. Mean impact force and maximum displacement at midspan.

mean impact force is expressed with the following equation.

$$
P_{\mathrm{m}}=\alpha \frac{1}{\delta_{\max }}
$$

where $\alpha$ is a proportionality constant. Based on the results of 20 experiments for a kinetic energy of $3750 \mathrm{~J}$ (shown in Table 2, from No 14 to 21) $\alpha$ is found as 2452 .

In the case of other impact energies from very few experimental results, we can observe that this relation is inverse proportional. The proportionality constant $\alpha$ in Eq. (3) has tendency to increase, for increasing impact energy $E_{\mathrm{col}}$. Therefore, a constant of proportionality $\beta$ for the impact energy $E_{\text {col }}$ is assumed as shown in Eq. (4).

$\alpha=\beta E_{\mathrm{col}}$.

From Eqs. (3) and (4), the maximum displacement $\delta_{\max }$ can be expressed by the Eq. (5).

$\delta_{\max }=\beta \frac{E_{\mathrm{col}}}{P_{\mathrm{m}}}$

The maximum displacement is proportional to the impact energy $E_{\mathrm{col}}$ and is inverse proportional to the mean impact

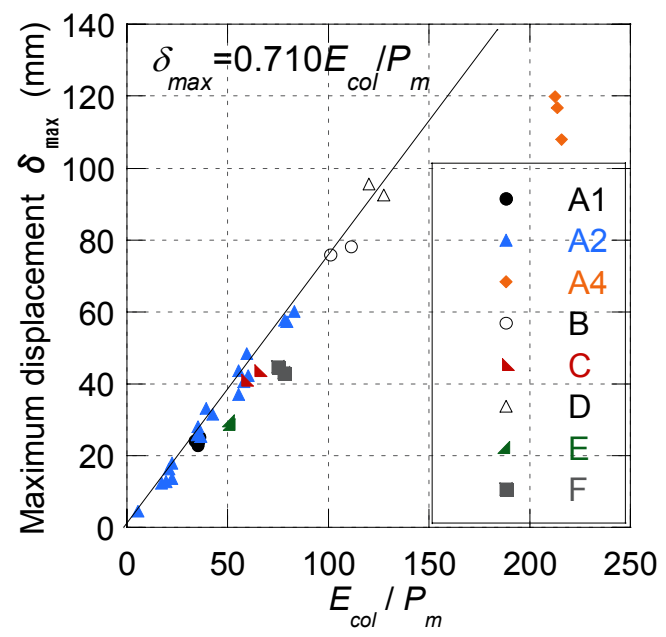

Fig. 11. Maximum displacements depending on $E_{\mathrm{col}} / P_{\mathrm{u}}$.

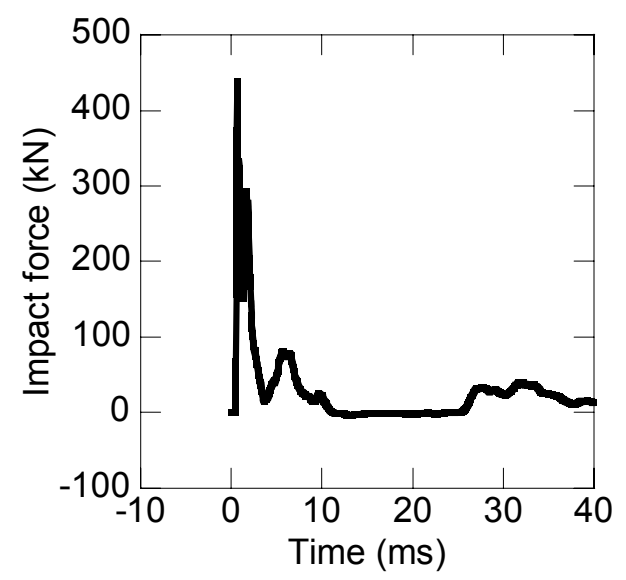

Fig. 12. Time response of impact force for test No. 16 (type A4, $m=300 \mathrm{~kg}, V_{\text {col }}=5 \mathrm{~m} / \mathrm{s}$ )

force $P_{\mathrm{m}}$. Figure 11 shows the relation between the maximum displacement $\delta_{\max }$ and the ratio impact energy to mean impact force $E_{\mathrm{col}} / P_{\mathrm{m}}$ for each a type of all reinforced concrete beam. The maximum displacement $\delta_{\max }$ is proportional to the ratio of impact energy to mean impact force $E_{\mathrm{col}} / P_{\mathrm{m}}$ for most of the beams, excepted for the beam type A4, where the maximum displacement is slightly smaller.

Figure 12 shows the time response of the impact force for test No. 16 (beam type A4, impact velocity $V_{\text {col }}=5 \mathrm{~m} / \mathrm{s}$ and mass $=300 \mathrm{~kg}$ ). The initial impact occurs within $10 \mathrm{~ms}$. After that, the impacting mass rebounds and no forces are transmitted from $10 \mathrm{~ms}$ to $25 \mathrm{~ms}$.

The natural period of beam type A4 is about $40 \mathrm{~ms}$. Therefore, the ratio of initial contact time to natural period $T_{\mathrm{d}} / T_{0}$ is about 0.25 . For the other experiments, the ratios are in the range of 2.4 to 5.2. Here, $T_{0}$ is the natural period of the beam shown in Table 1, $T_{\mathrm{d}}$ is the impact force duration, which was directly determined from time response as shown in Fig. 5 or 


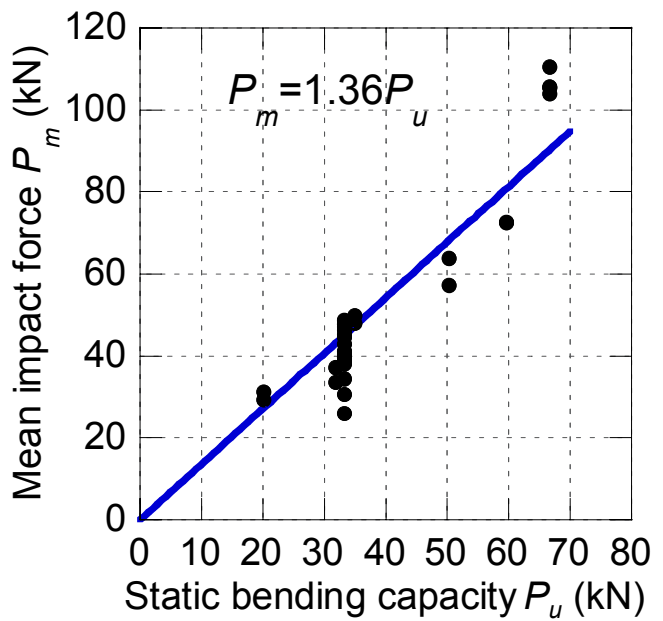

Fig. 13. Relationship between the mean impact force and the static ultimate bending capacity.

12. It can be considered that the influence of the duration of impact on the maximum deflection for the beam type A4 is small.

We excluded the beam type A4 shown in Fig. 11 for the approximation equation using the method of least squares. The maximum displacement $\delta_{\max }$ of the reinforced concrete beams is expressed with following equation.

$\delta_{\max }=0.710 \frac{E_{\mathrm{col}}}{P_{\mathrm{m}}}$

Here, the correlation coefficient $R^{2}$ is 0.962 and the duration of impact $T_{\mathrm{d}}$ used to calculate the mean impact force $P_{\mathrm{m}}$ is the duration of the first impact until rebound.

On the other hand, the mean force $P_{\mathrm{m}}$ is the impulse divided by the duration of impact force. In this study, the utilization of the mean force $P_{\mathrm{m}}$ is possible, due to the measurements of the impact force. However, it is generally difficult to predict this value $P_{\mathrm{m}}$. The ultimate bending strength $P_{\mathrm{u}}$ is the typical characteristic value for a reinforced concrete beam. If it is possible to use $P_{\mathrm{u}}$ instead of $P_{\mathrm{m}}$, the estimation of dynamic behavior becomes easily and it gives significant benefit towards a performance based design of structure under impact. There is a positive correlation between the mean impact force $P_{\mathrm{m}}$ and the static ultimate bending capacity $P_{\mathrm{u}}$ from Eqs. (1) and (2). Here, we assume an approximation expressed with the following equation visualized in Fig. 13.

$P_{\mathrm{m}}=1.36 P \mathrm{u}$.

From Eqs. (6) and (7), the following equation is drawn.

$\delta_{\max }=0.522 E_{\mathrm{col}} / P_{\mathrm{u}}$

Figure 14 shows the relationship between the maximum displacement $\delta_{\max }$ and the ratio kinetic energy to ultimate bending strength $E_{\mathrm{col}} / P_{\mathrm{u}}$, for which except for beam type A4,

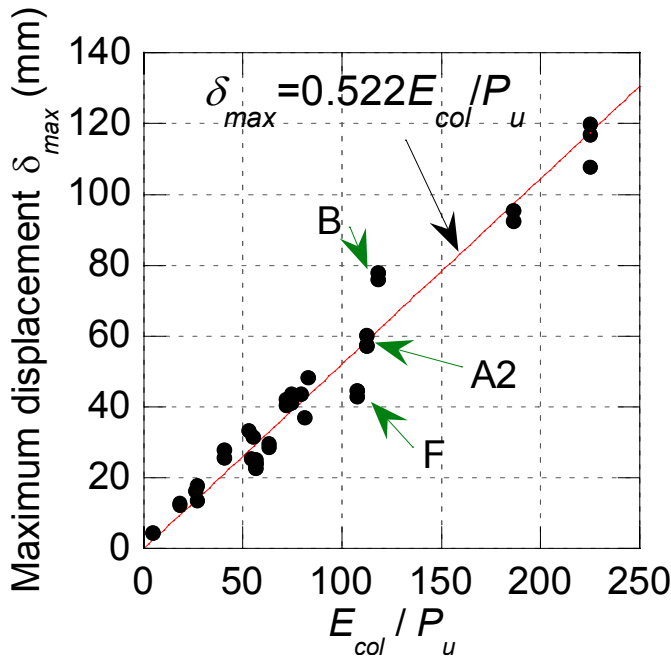

Fig. 14. Relationship between the ratio kinetic energy to ultimate bending capacity $E_{\mathrm{col}} / P_{\mathrm{u}}$ and maximum displacement $\delta_{\max }$.

the collision velocity is $5 \mathrm{~m} / \mathrm{s}$ and the impact mass is $300 \mathrm{~kg}$. It becomes clear that the maximum displacement $\delta_{\max }$ of the reinforced concrete beam can be calculated by the kinetic energy of the falling weight $E_{\mathrm{col}}$ and the static ultimate bending capacity $P_{\mathrm{u}}$. The maximum displacement of the beam types A2, B and F under same impact conditions $(m=300 \mathrm{~kg}$ and $V=5 \mathrm{~m} / \mathrm{s}$ ) are also shown in Fig. 14. It is seen that the maximum displacement of the beam type A2 suits well with the estimated Eq. (8), and that the maximum displacements of the beam types B and F slightly deviate from Eq. (8). Nevertheless, the static ultimate bending capacities of the three beams are almost similar. The bending stiffness EI of the three beams varies largely and they influence the absorbed energy and the maximum displacement. It is noted that the Eq. (8) is valid under the condition of the ratio initial contact time to natural period $T_{\mathrm{d}} / T_{0} \geq 2.4$.

\subsection{Verification of results}

In order to verify the proposed equation, results are compared with other experimental research (Kishi et al., 2000) and numerical results (Tachibana, 2007). The accuracy of the FEM analysis was evaluated by comparison with experimental results (Masuya et al., 2007). Figure 15 shows the details of the reinforced concrete beams used in the comparison, and Table 4 summarizes the impact conditions and the maximum displacements. The concrete design strength is $24.0 \mathrm{MPa}$, the yield stress of the main reinforcement is $345 \mathrm{MPa}$ and the yield stress of the shear reinforcement is $295 \mathrm{MPa}$. The diameter of the shear reinforcement is $6 \mathrm{~mm}$ for the beam type $\mathrm{G}$ and $10 \mathrm{~mm}$ for the beam type $\mathrm{H}$. The ultimate bending capacity is $49.0 \mathrm{kN}$ for the beam type $\mathrm{G}$ and $84.9 \mathrm{kN}$ for the beam type $\mathrm{H}$. An impact mass of $300 \mathrm{~kg}$ is used for all experiments. 
Table 4. Impact conditions and maximum displacements.

\begin{tabular}{lcccccc}
\hline Type & $\begin{array}{c}\text { Diameter } \\
\text { of bending } \\
\text { reinforcement }\end{array}$ & $\begin{array}{c}\text { Mass of } \\
\text { weight }\end{array}$ & $\begin{array}{c}\text { Impact } \\
\text { velocity }\end{array}$ & $\begin{array}{c}\text { Kinetic energy } \\
\text { of weight } \\
\text { at impact }\end{array}$ & $\begin{array}{c}\text { Ultimate } \\
\text { bending } \\
\text { capacity }\end{array}$ & $\begin{array}{c}\text { Maximum } \\
\text { displacement }\end{array}$ \\
& & $\begin{array}{c}M \\
(\mathrm{~kg})\end{array}$ & $\begin{array}{c}V_{\text {col }} \\
(\mathrm{m} / \mathrm{s})\end{array}$ & $\begin{array}{c}E_{\text {col }} \\
(\mathrm{J})\end{array}$ & $\begin{array}{c}P_{\mathrm{u}} \\
(\mathrm{kN})\end{array}$ & $\begin{array}{c}\delta_{\text {max }} \\
(\mathrm{mm})\end{array}$ \\
\hline G-1 & $\mathrm{D} 19$ & 300 & 5.0 & 3750 & 49.0 & 45.8 \\
G-2 & $\mathrm{D} 19$ & 300 & 6.0 & 5400 & 49.0 & 60.9 \\
H-1 & $\mathrm{D} 22$ & 500 & 3.13 & 2450 & 84.9 & 20.5 \\
H-2 & $\mathrm{D} 22$ & 500 & 4.20 & 4410 & 84.9 & 33.2 \\
G-2(FEM) & $\mathrm{D} 19$ & 300 & 6.0 & 5400 & 49.0 & 60.6 \\
H-2(FEM) & $\mathrm{D} 22$ & 500 & 4.20 & 4410 & 84.9 & 37.7 \\
A2(FEM) & $\mathrm{D} 13$ & 300 & 5.0 & 3750 & 33.3 & 58.9 \\
\hline
\end{tabular}
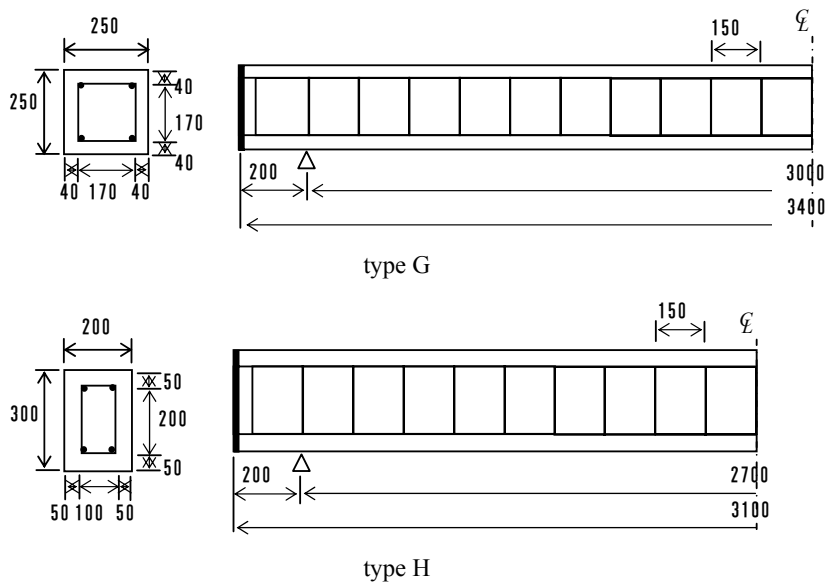

Fig. 15. Details of reinforced concrete beams.

Numerical analyses by FEM were carried out for the beam types G-2, H-1 and A2, shown in Table 1. The impact behavior of the reinforced concrete beams was analysed using the finite element code ADINA (Automatic Dynamic Incremental Nonlinear Analysis) (Bathe, 1996). Figure 16 shows the finite element model used for beam type A2.

Drucker-Prager yield criterion is used for the material model of concrete. A bilinear model is used for steel reinforcement, where $0.4 \%$ of the Young modulus $E_{\mathrm{S}}$ is used for the plastic hardening $H^{\prime}$.

Strain rate effects for concrete and steel are considered by means of a DIF (Dynamic Increase Factor). The DIF values for tensile and compressive strength for concrete and yield strength of steel reinforcement are $\mathrm{DIF}_{\mathrm{ct}}=1.2, \mathrm{DIF}_{\mathrm{cc}}=1.0$ and $\mathrm{DIF}_{\mathrm{s}}=1.2$, respectively.

These values are taken from research that aimed predicting the dynamic failures of reinforced concrete beams by means of various numerical methods (Kishi et al., 2008; Subcommittee of Impact Problems, 2004).

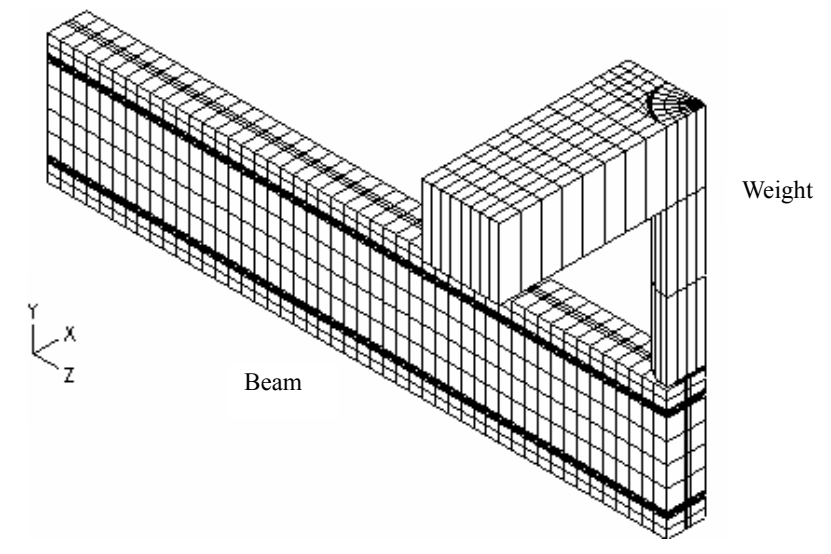

Fig. 16. Finite element model of quarter part of the beam and the weight.

Figure 17 shows the relation between these maximum displacements and impact energy divided by the static ultimate bending capacity with the proposed equation. The result from this equation is in good agreement with the additional experimental results and analytical results.

Therefore, it is considered that the proposed equation can be applied to estimate the maximum displacements of the reinforced concrete beams subjected to slow velocity impacts, which reach the inelastic range.

\subsection{Applicability for a performance based design}

Performance based design allows for satisfying performance requirements of structures without the restraint from the traditional design regulations. The impact loading is generally the most important action on protection structures such as rock sheds. Although rockfall is an accidental event for general structures such as bridges, it can be not considered as an accidental action for protection structures against rockfalls since protection of people from rockfalls is the 
Table 5. The levels of impact action and the performance criterions of a protection structure or a structural member.

\begin{tabular}{|c|c|c|c|c|c|}
\hline $\begin{array}{l}\text { Impact } \\
\text { action }\end{array}$ & $\begin{array}{l}\text { Explanation by occurrence } \\
\text { frequency }\end{array}$ & Damage & Safety & Serviceability & Repair \\
\hline Level 1 & $\begin{array}{l}\text { The action corresponding to the maximum } \\
\text { energy with the occurrence expected to be } \\
\text { once or twice during several decades or } \\
\text { the design working period of the road. }\end{array}$ & No damage & $\begin{array}{l}\text { Safe to traffic vehicles } \\
\text { and passing persons }\end{array}$ & No obstacle & No need \\
\hline Level 2 & $\begin{array}{l}\text { The action corresponding to the maximum } \\
\text { energy with the occurrence expected } \\
\text { to be within } 100 \text { years. }\end{array}$ & $\begin{array}{l}\text { Damage is } \\
\text { limited within } \\
\text { an allowable } \\
\text { range. }\end{array}$ & $\begin{array}{l}\text { Safe to traffic vehicles } \\
\text { and passing persons }\end{array}$ & No obstacle & $\begin{array}{l}\text { Small-scale } \\
\text { repair }\end{array}$ \\
\hline Level 3 & $\begin{array}{l}\text { The action corresponding to the largest } \\
\text { energy with the possibility of occurrence } \\
\text { by strong earthquake etc. }\end{array}$ & $\begin{array}{l}\text { There is no } \\
\text { fatal damage. }\end{array}$ & Safe to passing persons & $\begin{array}{l}\text { Traffic } \\
\text { restriction }\end{array}$ & $\begin{array}{l}\text { Repair or } \\
\text { reinforcement }\end{array}$ \\
\hline
\end{tabular}

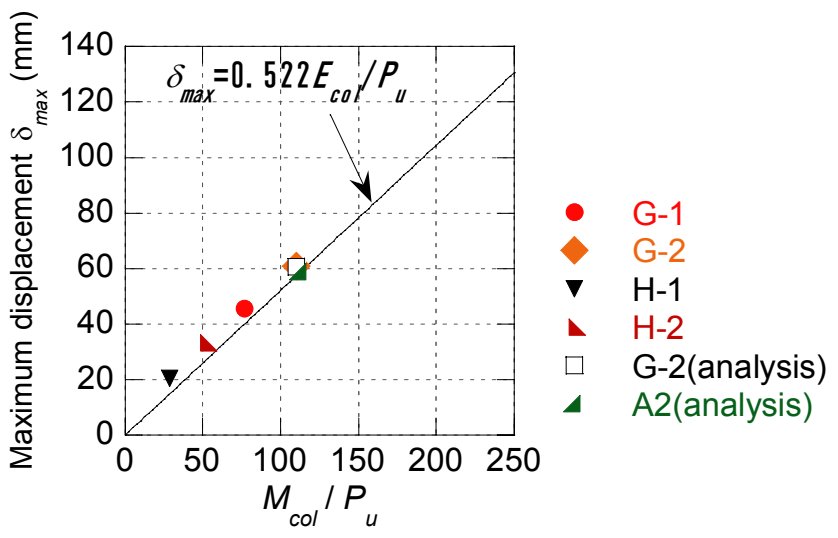

Fig. 17. Proposed equation and other results.

original purpose of the structure. Therefore, dealing with the impact load as an identified variable action or as an action based on a certain scenario seems more appropriate rather than as an accidental action. Table 5 shows exemplary levels of impact action and performance criterions of a protection structure. The relationships between the impact action levels and the performance criterions are generally related to the importance of the planed protection structure. It is consequently thought that the classification of the loads according to action levels is required for a performance based design.

Although the outcome of this research can not be directly applied to all types of protection structures, it shows a considerable concept to treat the flexural deflections of structures due to impact loading. Based on the action level shown in Table 5, the collision energy can be specified and the maximum displacement of the beam can be determined by Eq. (8). Consequently, it can be assesd whether the resulting damage of the beam satisfies the performance criterions shown in Table 5. Subsequently, it can be verified whether adjustments in the design are necessary. In a similar manner, the max- imum displacement of the beam can also be evaluated for other impact position and other support condition also can be evaluated in similar manner.

It is expected that the method shown here can be also applied to other protection structures in the future. For that scope, further experimental data is needed, with and without shock absorbing layers. This method can not be applied to cases where shear failure occurs. It is also necessary to have more research regarding the analysis technique such as Finite Element Method with high reproducibility (Masuya et al., 2006; Kishi et al., 2008), which would allow for further parameter studies and enhancement of the proposed equations.

\section{Conclusions}

Series of impact experiments were carried out aiming to obtain fundamental data to establish a performance based design of reinforced concrete beams with preceding bending failure (the margin degree of static shear capacity to static bending capacity $\alpha \geq 1$ ). The reinforcement, sectional dimensions and span lengths of the reinforced concrete beams were varied. The static ultimate bending capacity of these reinforced concrete beams ranges from $16.7 \mathrm{kN}$ to $66.7 \mathrm{kN}$. Also, the impact energy varies from $150 \mathrm{~J}$ to $5400 \mathrm{~J}$ based on the variation of mass and impact velocity. From the impact experiments various results and their relations were registered for the different beam types. Also the estimation of bending displacement of reinforced concrete beam due to impact has been investigated.

The results obtained by this study are concluded as follows:

1. The impulse resulting from the impact is proportional to the momentum of the impacting mass and the impact force duration, and is directly proportional to the momentum of the impacting mass divided by the 
static ultimate bending capacity $M_{\mathrm{col}} / P_{\mathrm{u}}$ with respect to all kind of reinforced concrete beams.

2. The maximum displacement is inverse proportional to the mean impact force. The maximum displacement is in proportional relation to the value of the mean impact force divided by impact energy $E_{\mathrm{col}} / P_{\mathrm{m}}$.

3. The relation between the mean impact force and the static ultimate bending capacity is shown. It is clear that the maximum displacement of the beam is almost proportional to the impact energy divided by the static ultimate bending capacity $E_{\mathrm{col}} / P_{\mathrm{u}}$.

4. It is determined that the estimated equation with respect to the maximum displacement of reinforced concrete beams can be calculated by the kinetic energy and velocity of the impacting mass and the static ultimate bending capacity. The verification of the proposed equation was made by comparisons with other experimental results and results from finite element method. It has been shown that the approach and the concept to estimate the maximum bending displacement of the structure under impact, allows for a performance based design of protection structures.

Acknowledgements. K. Schellenberg, C. di Prisco and anonymous referees made important contributions to the article. Nihon Samicon Co., Ltd provided a number of concrete specimens in this study. Many members of the subcommittee concerning performance based design of structures against impact action of JSCE gave the authors valuable comments and suggestions on various occasions. The authors would like to express sincere gratitude.

Edited by: K. Schellenberg

Reviewed by: C. di Prisco and four other anonymous referees

\section{References}

Bathe, K. J.: Finite Element Procedures, Prentice Hall, 1996.

Delhomme, F., Mommesin, M., Mougin J.-P., and Perrotin P. : Behavior of a structurally dissipating rock-shed: experimental analysis and study of punching effects, Int. J. Solids Struct., 42(14), 4203-4219, 2005.

Japan road association: Handbook of preventatives against rockfalls, Japan road association, Japan Road Association, 2000 (in Japanese).

Japan Railway Civil Engineering Association: Manual for preventive structures against rock falls, Japan Railway Civil Engineering Association, 1978 (in Japanese).

Kishi, N. and Miakmi, H.: An empirical impact resistant design formula of RC beams with statically bending failure mode, Japan Society of Civil Engineers, J. Struct. Earthq. Eng., No. 647/I-51, 177-190, 2000.

Kishi, N., Ando, T., Imoto, K., Kasai, Y., Katuki, S., Kambayashi, A., and Masuya, H.: Round-robin analysis on impact behaviour of RC beam subjected to a falling-weight impact force, Japan Society of Civil Engineers, J. Struct. Eng., 49A, 1299-1310, 2003.
Kishi, N., Ohno, O., Imoto, K., Ishida, M., Kasai, Y., Kanbayashi, A., and Masuya, H.: Round robin pre/post analysis of RC beam under falling-weight impact, Proceedings of International Symposium on Structures under Earthquake, Impact, and Blast Loading (IB'08), 217-224, 2008.

Kishi, N.: Numerical impact response analysis of rockfall protection galleries, Struct. Eng. Int., 19, 301-320, 2009.

Nakata, Y., Masuya, H., and Nishimura, Y.: Study on characteristic of impact behavior of reinforced concrete beam from the view of momentum and kinetic energy of collision body, Japan Society of Civil Engineers, J. Struct. Eng., 48A, 1493-1503, 2002.

Masuya, H.: Impact problem concerning rock falls and research activities of related field in Japan, Proc. of 6th Asia-Pacific Conference on shock \& impact loads on structures, CI-Premier Pte Ltd., 63-70, 2005.

Masuya, H. and Tachibana, S.: Simulation of behavior of reinforced concrete beam under impact, in: Proceedings of the 2nd international conference on design and analysis of protective structures against impact/impulsive/shock loads, Organized by the Defence Science \& Technology Agency of Singapore and Nanyang Technological University, 406-416, 2006.

Masuya, H. and Yamamoto, M.: Load resistant factor of rock-sheds in heavy snow area, Proceedings of the joint Japan-Swiss scientific seminar on impact load by rock falls and design of protection structures, 121-128, 1999.

Schellenberg, K., Volkwein, A., Roth, A., and Vogel, T.: Largescale impact tests on rock fall galleries, Proceedings of the 7 th International Conference on Shock and Impact Loads on Structure, CI-Premier Pte Ltd., 497-504, 2007.

Schellenberg, K.: On the Design of Rockfall Protection Galleries, Südwestdeutsche Verlag für Hochschulschriften, p. 186, 2009.

Sonoda, K.: Ultimate limit states of rockshed and design method, in: Proceedings of the joint Japan-Swiss scientific seminar on impact load by rock falls and design of protection structures, edited by: Masuya, H. (Kanazawa University) and Labiouse, V. (Swiss Federal Institute of Technology Lausanne), 129-136, 1999.

Subcommittee of Impact Problems of JSCE: Practical methods for impact test and analysis, edited by: Kishi, N., Japan Society of Civil Engineers (JSCE), 2004.

Subcommittee concerning performance based design of structures against impact action of JSCE: Design method of structures under impact action by concept of performance based design, edited by: Masuya, H., Japan Society of Civil Engineers (JSCE), Structural Engineering Technical Series No. 52, 2007.

Tachibana, S.: Study on dynamic behavior and performance of reinforced concrete beams under impact, Doctor of Engineering thesis, Kanazawa University, Dissertation No. 2863, 2007.

Tachibana, S., Masuya, H., and Nakamura, S.: Experimental study on the impact behavior and performance of reinforced concrete beam with some absorbing materials, Proceedings of the $31 \mathrm{st}$ conference on our world in concrete \& structures, CI-Premier Pte Ltd., 387-398, 2006.

Yamamoto, M., Masuya, H., Onda, S., Horie, T., and Kumagai, T.: A study on the impact test method and characteristics of behavior of reinforced concrete beam by a weight drop, Japan Society of Civil Engineers, J. Struct. Eng., 47A, 1683-1694, 2001. 